\title{
Da perversão à expiação: uma mudança de perspectiva*
}

Eduardo Hugo Frota Neto

Ana Maria Rudge

\begin{abstract}
Neste trabalho é analisada a influência que a Medicina Legal teve na delimitação do conceito de perversão, e esboçada outra abordagem, que identifica o perverso com uma entidade do imaginário social cuja função é promover a coesão da coletividade em torno de e contra si - um bode expiatório. Busca-se deslocar a pesquisa em direção aos mecanismos e necessidades psíquicas e sociais que fomentam a psicodinâmica da expiação, ou o engendramento de bodes expiatórios.
\end{abstract}

Palavras-chave: Psicanálise, perversão, Medicina Legal, bodes expiatórios

* Trabalho realizado no grupo de pesquisa Figuras do Trauma - Pontifícia Universidade Católica do Rio de Janeiro - PUC/RJ.

Trabalho parcialmente baseado na dissertação acadêmica Pela travessia da perversão: leitura crítica de suas configurações psicanalíticas, 2005, Pontifícia Universidade Católica do Rio de Janeiro - PUC/RJ.

Trabalho apresentado no Encontro/Curso Avançado "O sujeito e a sexualidade na aurora do século XXI”, Universidade Estadual do Rio de Janeiro, agosto de 2007. 
Talvez a psicanálise esteja vivendo certo esforço no sentido de repensar a perversão. Um rápido levantamento bibliográfico produz como resultado um grupo razoavelmente numeroso e recente de obras psicanalíticas sobre o tema. Estas, no entanto, apesar de terem em comum, como não poderia deixar de

ser, as elaborações de Freud, formam um conjunto algo heterogêneo, agrupadas principalmente pela referência ao próprio significante "perversão".

Os pressupostos que o motivam, por sua vez, são um verdadeiro amálgama. O que o termo delimita, no senso comum, é uma nebulosa de sexualidade anormal e defeito moral, um campo que ganhou legitimidade científica e consistência conceitual através da Medicina Legal do século XIX.

Ora, foi com esta tradição que Freud rompeu, subvertendo ponto a ponto suas premissas, explicitamente a partir dos "Três ensaios sobre a teoria da sexualidade" (Freud, 1905). O abandono da noção de uma "atração recíproca natural de um sexo pelo outro" (Valas, 1990, p. 9), já em 1905, lança Freud na radical contingência de alvos e objetos para a pulsão, o que dificulta muito pensar na perversão como mero desvio sexual: "a hipótese mais simples e mais indicada sobre a natureza da pulsão seria que, em si mesma, ela não possui qualidade alguma, devendo apenas ser considerada como uma medida da exigência de trabalho feita à vida anímica" (Freud, 1905, p. 159).

A perversão, se definida como desvio da sexualidade genital e procriativa, dilui-se, em Freud, em um fundo universal de pura polimorfia pulsional, mormente nos primórdios da vida anímica. As organizações pulsionais proscritas pela cultura tornam-se quando possível matéria-prima de sublimações e formações reativas, ou são recalcadas e dão origem a sintomas. Os níveis de rigidez e exclusividade de alvos e escolhas de objetos sexuais - em qualquer configuração da sexualidade - são o índice possível de seu caráter patológico. De qualquer forma, a sexualidade deixa de ser entendida nos termos de uma tipologia para ser imersa em uma série de contingências que di- 
zem respeito à história de cada sujeito singular, e qualquer resultado razoavelmente estável, qualquer configuração sexual adulta passa a ser entendida como um verdadeiro mosaico.

A origem da teoria da sexualidade infantil pode ser localizada no famoso momento do abandono, por Freud, de sua teoria da sedução - documentado na carta 69 (Freud, 1897) - a que se refere como sua neurotica. A partir deste abandono, "a noção do sedutor perverso perde sua consistência" (Valas, 1990, p. 18), vale dizer, ele passa a existir, primeiramente, como personagem do discurso neurótico. Esta ênfase na realidade psíquica terá grande impacto no que Freud nos deixou, notavelmente a partir dos anos 1920, como seu último esboço de classificação diagnóstica, em que o termo "perversão" tem um papel bastante periférico.

A perversão como categoria diagnóstica torna-se problemática desde que a neurose é situada como uma "perversão negativa" (Freud, 1905). Mais tarde, é no contexto de uma discussão sobre o fetichismo que Freud elabora o conceito de Verleugnung, um mecanismo psíquico que ultrapassa amplamente o campo da perversão, ora ocupando o papel de defesa que instaura uma psicose, ora sendo reconhecido como operando nos mais variados fenômenos, do déjà-vu às crenças religiosas, passando, na clínica, por casos de neurose obsessiva.

Outro ponto de inflexão importante, enfim, permeia seus escritos sobre a civilização. A tensão progressivamente valorizada entre as pulsões e a moral acaba por matizar decisivamente o entendimento psicanalítico da própria moralidade, na medida em que este conflito dá origem a um novo objeto metapsicológico, representado pela instância universal do supereu. Daí decorre outra visão não só da crueldade, mas também do crime, da infração e da transgressão.

De fato, a perversão como defeito moral é a mais estranha à teorização freudiana. Alguns temas que tangem a questão da perversidade, no entanto, são ocasionalmente abordados, como é o caso da crueldade, do elemento de dominação que participa da sexualidade masculina e da influência do sentimento de culpa inconsciente ou necessidade de punição na motivação para o crime. Mas, no fundo, trata-se sempre de investigar os destinos e possibilidades de sublimação de moções pulsionais que nos são comuns.

Estes indícios de uma nova orientação diante da perversão às vezes não surtem efeito. Encontram-se, na literatura psicanalítica recente, embarcados no termo "perversão", precipitados oitocentistas em graus diversos, aparecendo ora pela primazia da genitalidade tomada como doutrina, ora pela reificação do termo em uma estrutura diagnóstica justificada através do mecanismo da Verleugnung, ora pela referência à crueldade (ou simplesmente ao mal) como critério suficiente para dividir as águas de uma ética psicanalítica.

A concepção pré-psicanalítica de perversão continua a contaminar as elaborações psicanalíticas sobre a perversão em vários âmbitos. Encontramos ressonân- 
cias do âmbito médico-legal em que se inseria a perversão no final do século XIX, designando os assassinos, necrófilos, sádicos e delinquentes, atravessando as elaborações sobre a perversão, em que o substantivo "perversidade" frequentemente se insere (Rudge, 2004).

Foucault (2001) discutiu longamente a constituição de uma figura, que chama de "o anormal", em sua relação, por um lado, com o campo dos desvios sexuais e, por outro, com o crime, amálgama que parece permear o senso comum até hoje e estabelecer grandes confusões na teorização do que se define como perversão. É no século XIX que tanto esse autor quanto Lanteri-Laura (1994) localizam a origem da perversão como conceito científico, sugerindo ser este o produto de uma aproximação entre medicina e poder judiciário.

Desde os anos 1815-1820, vemos júris criminais declarar[em] que alguém é culpado e, depois, ao mesmo tempo, pedir[em] que, apesar da culpa afirmada pela sentença, seja mandado para um hospital psiquiátrico por ser doente. Portanto os júris começam a estabelecer o parentesco, a pertinência, entre loucura e crime (...). Trama-se, pois, pouco a pouco, essa espécie de continuum médico-judiciário (...). Essa prática, essa técnica da dupla qualificação organiza o que podemos chamar de domínio da "perversidade", uma noção curiosíssima que começa a aparecer na segunda metade do século XIX. (Foucault, 2001, p. 40-41)

Lanteri-Laura (1994), por sua vez, assinala que é no século XIX que "o estudo supostamente científico dos comportamentos comumente tidos por perversos" vai se transformar, "em razão do desenvolvimento das perícias judiciárias (...) num bem legítimo e inconteste da medicina” (p. 10).

Em 1830 (...) a burguesia liberal havia tomado o poder e, pouco a pouco, teve cada vez menos necessidade da ideologia libertária que antes lhe fora tão útil. A religião, em que ela não acreditava desde longa data, não podia servir-lhe para nada; e a herança do Século das Luzes não a garantia nem contra os perigos, nem contra o fascínio das singularidades mais extremas da vida sexual. Ela precisava de razões para se precaver contra elas, de razões em que pudesse confiar: o discurso médico chegou em boa hora. (p. 28)

Nessa época, por exemplo, foram cunhados muitos dos termos dos quais Freud se apropriou e que até hoje usamos: sadismo, masoquismo, fetichismo, narcisismo, entre outros. Nas histórias de caso descritas em 1886 por Krafft-Ebing (2000) - psiquiatra alemão oitocentista - encontramos, em meio a toda esta terminologia, indícios da injunção histórica que formou o contexto de onde adveio o conceito de perversão.

A obra maior de Krafft-Ebing é considerada a mais conhecida síntese das ideias de seu tempo sobre nosso tema: "a Psychopathia sexualis (...) tornou-se clássica e (...) constituiu, ao mesmo tempo, um tesouro e um catecismo" (Lanteri-Lau- 
ra, 1994, p. 102-103). Os casos clínicos que relatou, particularmente, tornaram-se verdadeiros paradigmas de perversões, às vezes até de forma bastante acrítica:

Krafft-Ebing tornou-se, assim, o ponto zero da interpretação: foi como se se admitisse que o estabelecimento dos dados clínicos havia-se consumado sem nenhum pressuposto, e no despojamento do respeito aos "fatos em si", e que seu conteúdo, sem nenhuma renovação, podia servir indefinidamente. (p. 103)

O termo "perversão" em seu discurso aparece, na forma adjetiva, para caracterizar o que constitui um conjunto de excitabilidades qualitativamente inadequadas. Fora do eixo quantitativo, onde se delimitam as "anestesias" e as "hiperestesias", as maneiras perversas de manifestar a sexualidade serão agregadas sob o termo "parestesias" e sua inadequação será justificada em função da preservação da espécie. Assim, Ebing "situa antecipadamente o problema em referência à procriação, tomada como norma" (p. 26).

$\mathrm{Na}$ descrição e batismo dos casos clínicos, no entanto, percebe-se que a referência à genitalidade não dá conta sozinha de explicar a lógica de delimitação do campo em estudo. Significativamente, por exemplo, o único caso, entre os 238 descritos, que merece o exato diagnóstico de "perversão" não se apresenta em contradição à procriação ou mesmo à genitalidade:

Um de meus pacientes (...) casado com uma mulher extremamente bela (...) ficava impotente quando via sua pele alva (...). Mas, no isolamento de um passeio com ela pelo campo, acontecia de ele subitamente forçá-la ao coito no meio da campina ou atrás de um arbusto. Quanto mais ela se recusasse mais excitado ele ficava, com plena potência (...). Mas em casa, na sua própria cama, era totalmente destituído de desejo. (Krafft-Ebing, 2000, p. 21)

Por que este paciente, entre tantos, mereceu o mais específico diagnóstico de "perverso"? O que nele se apresenta como a essência do campo da perversão, já que não é um desvio nem quanto à genitalidade nem quanto à procriação? Não nos ajuda, tampouco, o recurso à dimensão quantitativa: a impotência neste caso não é uma simples anestesia, já que depende de circunstâncias bastante específicas. Como havia reservado a qualidade de perversas às excitabilidades suscitadas por estímulos inadequados, Krafft-Ebing se depararia aqui com a impossível tarefa de argumentar cientificamente pela adequação do estímulo "cama" e a inadequação do estímulo "passeio pelo campo".

É claro que o problema é outro: o que se insinua, através do forçar ao coito e do fato de a resistência da vítima acentuar a excitação, são a violência e a dimensão bizarra quanto à sexualidade ideal que dão consistência conceitual ao diagnóstico de perversão. 
A influência da moralidade aparecia de forma bem crua na maioria das descrições: Krafft-Ebing (2000) escreve que o protagonista do caso 15, por exemplo, em determinado momento "apresentou inclinação para o mal" (p. 22), e que o do caso 18 , "desde a mais tenra infância, tinha uma natureza ruim" (p. 24). Esta influência não pôde ser tematizada explicitamente pelo autor - se o fosse entraria em contradição com seu viés positivista, científico - mas conduzia, não obstante, sua nosografia. Este estranho estado de coisas devia sua sustentação, de fato, aos propósitos práticos a que servia.

Há uma série de casos agrupados sob o curioso diagnóstico de "assassinato por luxúria" nos quais a psicopatologia sexual oitocentista revela sua estreita vinculação com o campo jurídico. Estes casos, 13 no total, compartilham certas características. Uma delas, decorrente da influência da moralidade, é a ênfase na crueldade em detrimento do que é considerado sexual no resto dos casos. Em alguns chega a ser difícil perceber o que há de luxúria nos assassinatos descritos. No caso 17, aliás, o de Jack, o Estripador, Krafft-Ebing admite que "nada indica que ele mantivesse relações sexuais com suas vítimas, mas é muito provável que o ato homicida e a subsequente mutilação dos cadáveres fossem equivalentes do ato sexual" (p. 23).

É interessante perceber que uma ampliação da noção de sexualidade, tão combatida quando proposta um pouco mais tarde por Freud de forma muito mais detalhada, extensa e consistente, já está antecipada aqui sem maiores explicações, e não se constitui como um problema.

A diferença, há que se perceber, é tão sutil quanto decisiva. A intuição de Krafft-Ebing incluía o assassino entre os desviantes sexuais para tornar a infração uma categoria diagnóstica, ao custo de uma vinculação confusa com a sexualidade não genital. A impressão é que o sexual como entendido então, na maioria dos casos, é mero coadjuvante, e o mais importante acaba sendo a delimitação de um campo de anormalidade moral. Um campo médico, sexual, difuso o suficiente para que a medicina pudesse tomar como objeto terapêutico, entre outros, qualquer tipo de infração legal, mas restrito o suficiente para que se diferenciasse decisivamente de seu oposto, o campo da normalidade, assim preservando-o.

A ênfase na crueldade em detrimento do sexual aponta então para a heterogeneidade empírica em que se baseou o termo "perversão" e para como seu valor se apoiou na possibilidade de delimitar um campo de exclusão social, de anomalia. É isto, e não a sexualidade, o que perpassa implicitamente todos os casos de Krafft-Ebing, do "delírio erótico" ao "aviltamento de mulheres", da "homossexualidade" ao "canibalismo", passando por coisas como "metamorfose psicossexual", "bolinagem" e "insanidade periódica". A perversão vai de Jack, o Estripador, a "impulsos perversos" tais como "rir de coisas sérias, jogar dinheiro na água e correr sob uma chuva torrencial" (p. 39). 
Outra característica é que cinco dos "assassinatos por luxúria" começam pela descrição das vítimas, ao contrário da totalidade dos casos com outro diagnóstico, que se iniciam pela caracterização do "protagonista". O caso 18 é exemplar: "em 31 de agosto de 1895, o pastor Portalier, 17 anos, foi encontrado nu no campo. O ventre estava estripado e o corpo apresentava ainda outros ferimentos. A autópsia mostrou que a vítima fora primeiro estrangulada. Em 4 de agosto de 1897, um vagabundo chamado Vacher foi detido como suspeito" (p. 23).

O texto é bastante literário para um tratado científico: parece ter saído, mais especificamente, de um romance policial. E policial é um termo-chave: começa a ficar claro que a definição de patologia se adapta a finalidades jurídicas. Basta perceber, por exemplo, o quanto o autor está preocupado com a imputabilidade dos casos analisados ou com que frequência encerra o relato de um caso por seu veredicto ou sentença judiciária.

Os laços do sistema de Ebing com as questões jurídicas apontam para o quanto a medicina teve que se distanciar da vocação clínica de seus critérios de avaliação para agregar sujeitos infratores a seus objetos de intervenção. É como se a anamnese destes sujeitos começasse pela turbulência que causaram no tecido social. Suas histórias de vida serão retrospectivamente descritas tendo a turbulência como norte. Eles não falam, nem mesmo através de seus atos, já que quem os interpreta parte de uma identificação com a vítima e chega, no final da descrição, a uma identificação com o juiz. Mais importante do que tratar era construir os critérios de separação entre o joio e o trigo que permitiriam assegurar um lugar permanente para a medicina no poder judiciário: "daí resultou, no final das contas, a separação entre os bons e os maus perversos, e a psiquiatria leiga se afigura, sem grande respeito humano, uma espécie de juízo final médico, onde à esquerda eram dispostos os bodes expiatórios e, à direita, as ovelhas" (Lanteri--Laura, 1994, p. 45).

A terceira característica dos "assassinatos por luxúria" desvenda como este saber mantém seu estatuto médico-científico, resguardando-se de uma total assimilação às contingências e pontualidades das questões judiciárias. Como, em um tratado de psicopatologia, entre casos de sadismo, masoquismo e outros "ismos" - termos que indicam estruturas, ou estados razoavelmente constantes -, figuram em pé de igualdade estes sujeitos capturados por seu(s) ato(s)? Vê-se o assassinato servindo como ponto de suporte principal do diagnóstico, um ato estendido, não obstante seu caráter pontual, ao sujeito como um todo, para que este pudesse continuar sendo um objeto para a psiquiatria. Definido por suas vítimas e seus atos "vis" e "horríveis" (termos recorrentes nas descrições de Krafft-Ebing), torna-se uma figura improvável, que exige a transformação de atos criminosos em estruturas de caráter. Esta vinculação, algo precária, era cimentada pela referência a estigmas, características físicas que remetiam a uma dimensão monstruosa. 
O que se busca, para demonstrar que se trata de alguém psiquiatrizável (...) não é um processo, mas estigmas permanentes que marcam estruturalmente o indivíduo. (...) $\mathrm{O}$ ato e os estigmas se referem - uns e outros, e de certo modo no mesmo plano, mesmo se sua natureza é diferente - a um estado permanente, a um estado constitutivo, a um estado congênito. As dimorfias [sic] do corpo são, de certo modo, as consequências físicas e estruturais desse estado, e as aberrações de conduta (...) são suas consequências instintivas e dinâmicas. (Foucault, 2001, p. 379-380)

Os dismorfismos estão, de fato, presentes na "Psychopathia sexualis". Do protagonista do caso 236, por exemplo, diagnosticado como "mania homicida", "o rosto era (...) assimétrico; o lado direito da face mais desenvolvido que o esquerdo; o nariz 'notavelmente irregular'" (Krafft-Ebing, 2000, p. 299). Nos casos 216 e 217 (que são "assassinatos por luxúria”) também aparecem assimetria e desproporção: o primeiro tinha uma "cabeça anormal, arredondada" (p. 280) e o segundo "era um homem alto (mais de 1,80 m), ligeiramente encurvado para a frente. Testa baixa, ossos malares muito proeminentes, osso maxilar maciço; olhos pequenos, estreitos e inflamados, olhar penetrante; pés grandes, mãos como garras de pássaro, andar bamboleante" (p. 280).

Em resumo, o campo psiquiátrico da perversão que inicialmente inspirou Freud era bastante comprometido com demandas jurídicas e produziu uma entidade nosográfica estrutural baseada na convergência entre crueldade e desvio da genitalidade. O amálgama "perversão" deixa assim entrever necessidades e dinâmicas psicossociais insuspeitadas, já que no fundo ele vem responder a uma demanda social de culpabilização. As parestesias convivem aí de forma confusa com a monstruosidade, e o resultado dessa teorização acaba sendo não simplesmente uma psicopatologia sexual, mas a construção de "um certo personagem que foi oferecido, de certo modo, ao aparelho judiciário, um homem incapaz de se integrar ao mundo, que gosta da desordem, que comete atos extravagantes ou extraordinários, que odeia a moral, que renega as leis desta e pode chegar ao crime" (Foucault, 2001, p. 22).

Essa figura, enfim, grosso modo, é o perverso em sua origem. É neste locus também que se desenha o que outro autor, René Girard, entende por bode expiatório, cuja periculosidade real ou fantasiada é elemento fundamental à sua eficiência em polarizar multidões em torno de e contra si. O objetivo desta polarização, por sua vez, a vitimação do algoz, constitui o processo expiatório.

A obra de René Girard nos permite entender a figura do perverso como um dos mais recentes desdobramentos desta entidade do imaginário social cuja função é assumir a culpa de todos e apresentar-se como causa de um mal-estar coletivo. O papel de algoz é, dentro de certos limites bastante flexíveis, negociável, sendo ao menos minimamente indiferente que uma ou outra pessoa o desempenhe. 
O sistema de Girard (2004) tem raízes em uma problemática psicológica, a do desejo, entendido como essencialmente mimético: só se deseja o que um outro deseja ou possui, o que um outro aponta como desejável. Disto decorre um pano de fundo de irredutível rivalidade para as relações humanas que, deixada sem freios, tende a desenvolver-se exponencialmente e levar qualquer agrupamento ao extermínio mútuo através da violência recíproca e generalizada - a má reciprocidade "dos insultos, dos golpes, da vingança" (p. 21).

Cada sociedade, tribo, coletividade que passou a existir e funcionar como tal através da superação de uma crise semelhante o fez marcada pelas idiossincrasias de sua experiência específica, mas a linha geral do processo que leva do caos à civilização é sempre a mesma: a união de todos contra um, o que transforma a violência recíproca em violência unânime. "O antagonismo de todos contra todos dá lugar à união de todos contra um único" (Girard, 1990, p. 104).

$\mathrm{O}$ apaziguamento e a integração que este linchamento fundador promove baseiam-se na canalização da violência de todos em direção a um único alvo, que passa a ser percebido como a fonte e causa única de toda violência, dando origem a uma entidade que Girard batiza de duplo monstruoso, uma entidade que é qualquer um porque é todos, é o outro de cada um e de todos, o rival por excelência, uma figura marcada pela "alteridade radical do monstro" (p. 206).

O monstro encarna a essência da violência recíproca, da qual todos participam, mas na qual são incapazes de se reconhecer. Ele é a verdade da relação antagônica entre os homens, teimosamente recusada, que acaba se impondo vinda de fora, como uma entidade alheia àqueles que a percebem. Girard descreve o fenômeno como alucinatório, pondo assim em relevo o movimento excorporativo que o caracteriza, a distância que se produz neste momento entre aquele que vê e aquilo que é visto - o monstro. O duplo monstruoso é a totalidade da violência, a "identidade onipresente da violência" (p. 201), fora, inclusive, de qualquer temporalidade: "é na eternidade que ele a assume" (p. 346). É esta entidade o verdadeiro objeto da violência unânime, encarnada em um indivíduo qualquer.

A unanimidade, no entanto, é efêmera, e deve ser refeita periodicamente através de repetições agora intencionais e planejadas do espontâneo e arbitrário linchamento primordial, práticas profiláticas, por assim dizer, de prevenção à violência recíproca. Contra seu eventual retorno desenvolve-se aos poucos todo um saber fazer sacrificial, na escolha das vítimas, por exemplo, nas quais o autor identifica características recorrentes que seguem uma lógica própria. É necessário "sacrificar uma vítima tão semelhante quanto possível ao duplo monstruoso" (p. 339).

As características das vítimas coletivas irão todas se remeterem a esta entidade, a quem devem a unidade subjacente à pletora de suas manifestações. Colocando-se a tarefa de "enumerar os traços que tendem a polarizar as multidões violentas contra aqueles que os possuem" (Girard, 2004, p. 28), o autor acabará por 
se referir, usando expressões distintas, a três dimensões ou aspectos diferentes do entendimento de tais traços: a dimensão das "marcas vitimárias", a dos "crimes indiferenciadores" e a das "categorias sacrificáveis".

As marcas vitimárias dizem respeito àquelas características que fazem a vítima evocar e representar a indiferenciação caótica de um agrupamento em crise, "tudo aquilo que sugere sua afinidade culpável com a crise" (p. 33). Quaisquer traços que demonstrem, por sua própria existência, a fragilidade e instabilidade de um sistema de diferenças estão aptos a tornar seu portador um símbolo da crise social mais ampla e, portanto, um candidato a bode expiatório. Aqui reencontramos os dismorfismos, as aberrações físicas, que colocam em xeque a tranquilizadora concepção do corpo humano como sistema estável de diferenças anatômicas.

Se a enfermidade, mesmo acidental, inquieta, é porque ela dá uma impressão de dinamismo desestabilizador. Ela parece ameaçar o sistema como tal. Procura-se circunscrevê-la, mas não se consegue; ela ajunta ao seu redor as diferenças que se tornam monstruosas, elas se precipitam, se encaixam, se misturam e, por fim, ameaçam extinguir-se. (p. 31)

Esta inquietação - que se manifesta como uma espécie de aversão, "um ligeiro recuo diante da anormalidade física" (p. 26) - é o que transforma em marcas vitimárias não só as deformações e mutilações mas também, de forma mais ampla, a loucura e a doença (p. 26). Por evocarem a crise com o próprio processo da doença, loucos e enfermos estão propensos à vitimação, servindo como metáfora da crise social indiferenciadora.

Uma segunda dimensão de traços recorrentes diz respeito aos crimes de que são acusadas as vítimas: "sempre se trata de infanticídio ritual, de profanações religiosas, de relações incestuosas e de bestialidade" (p. 25), rol no qual se incluem o regicídio, o parricídio e a violação (p. 22).

Por um lado tais crimes "contagiosamente indiferenciadores" (p. 23) representam uma lesão aos próprios fundamentos da ordem cultural, às "diferenças familiares e hierárquicas sem as quais não haveria ordem social” (p. 22-23). Isto autoriza e facilita a crença segundo a qual "um pequeno número de indivíduos ou até mesmo um só pode tornar-se extremamente nocivo para toda a sociedade, apesar de sua relativa fraqueza. (...) Para que malfeitores, até diabólicos, consigam indiferenciar toda a comunidade, é preciso que a firam diretamente no coração ou na cabeça" (p. 23).

Mas não é apenas indiferenciação o que os crimes que polarizam perseguidores representam: eles também representam a violência máxima, e por isso colocam em movimento o desejo mimético, "que sempre acaba tendo como objeto a violência outra, a violência do outro. O desejo mimético exacerbado 
deseja ao mesmo tempo destruir e absorver a violência encarnada" (Girard, 1990, p. 347).

A estas duas dimensões virá se somar um aspecto mais técnico do saber fazer sacrificial, mesmo que necessariamente insuspeitado pelos próprios perseguidores. Como em "Totem e tabu" (Freud, 1912-13), a vítima original, a vítima do linchamento fundador, embora seja membro do agrupamento inicial, não é membro da coletividade, pois esta só se funda a partir de sua morte. A coletividade emerge do caos após vitimar alguém que só será entendido como um de seus membros retrospectivamente. As vítimas subsequentes devem, pois, reproduzir este estado de paradoxal exterioridade interna, sendo a exterioridade o que garante a eficácia do mecanismo expiatório no sentido em que ele cessa a má reciprocidade vingativa: a vítima ideal não é vingada por ninguém.

Aqueles que satisfazem esta condição constituem o que Girard (1990) chama de categorias sacrificáveis: prisioneiros de guerra, escravos, estrangeiros, marginais, "que apresentam um vínculo muito frágil ou nulo com a sociedade (...), incapazes de tecer com a comunidade os mesmos laços que ligam seus membros entre si” (p. 24).

Para que a vítima possa polarizar as tendências agressivas, para que a transferência possa se efetuar, não pode haver solução de continuidade, devendo ocorrer um deslizamento "metonímico" dos membros da comunidade às vítimas rituais; em outros termos, é preciso que a vítima não seja nem demasiado nem insuficientemente estrangeira a esta mesma comunidade (p. 338-339).

Esta exterioridade interna, esta marginalidade que a vítima encarna, se enraíza ainda na própria experiência excorporativa, diríamos, do duplo monstruoso que é, além de avatar da indiferenciação e rival máximo, ao mesmo tempo duplo, igual, e monstro, outro.

Nesta entidade encontramos, em resumo, todas as características do perverso oitocentista, entendido agora, sob um ponto de vista social, coletivo, como vítima: "a vítima expiatória é transfigurada: é esta transfiguração que protege a comunidade da violência, que pró́be aos fiéis de se considerarem uns aos outros como passíveis de substituir esta vítima original, e que os impede, portanto, de recair na violência recíproca" (p. 338).

De toda esta reorientação advêm novas possibilidades de pesquisa. Se deixarmos de lado o objetivo - comum à maioria das teorizações da perversão - de localizar os mecanismos propriamente perversos, de esquadrinhar o campo em busca de traços essenciais que permitam delimitá-lo, de definir, enfim, com segurança, a perversão como uma entidade diagnóstica, uma estrutura clínica, e se, ao invés disso, buscarmos e colocarmos em questão as condições de possibilidade de sobrevivência deste conceito diante da visada crítica de Freud, das grandes novidades que instaura no estudo do tema, suficientes, aliás, para descaracterizá-lo, encon- 
traremos, não no perverso, mas no olhar que o visa, todo um campo de análise que promete resultados proveitosos.

\section{Referências}

Foucault, M. Os anormais: curso no Collège de France (1974-1975). São Paulo: Martins Fontes, 2001.

Freud, S. (1897). Extratos dos documentos dirigidos a Fliess - carta 69. In: Edição Standard Brasileira das Obras Psicológicas Completas de Sigmund Freud. Rio de Janeiro: Imago, 1996. v. I.

. (1905). Três ensaios sobre a teoria da sexualidade. In: Edição Standard Brasileira das Obras Psicológicas Completas de Sigmund Freud. Rio de Janeiro: Imago, 1996. v. VII.

. (1912-13). Totem e tabu. In: Edição Standard Brasileira das Obras Psicológicas Completas de Sigmund Freud. Rio de Janeiro: Imago, 1996. v. XIII.

GIRARD, R. A violência e o sagrado. São Paulo: Editora Universidade Estadual Paulista, 1990. . O bode expiatório. São Paulo: Paulus, 2004.

Krafft-Ebing, R. von. Psychopathia sexualis: as histórias de caso. São Paulo: Martins Fontes, 2000.

Lanteri-Laura, G. Leitura das Perversões. Rio de Janeiro: Jorge Zahar, 1994.

Rudge, A. M. Aspectos do discurso perverso. In: XIII FÓRUM INTERNACIONAL DE PSICANÁLISE DA IFPS, 13., ago.2004, Belo Horizonte, MG.

VALas, P. Freud e a perversão. Rio de Janeiro: Jorge Zahar, 1990.

\section{Resumos}

(De la perversión a la expiación: un cambio de perspectiva)

En este trabajo se analiza la influencia que tuvo la Medicina Legal en la delimitación del concepto de perversión, y se esboza otro abordaje, que identifica el perverso con una entidad del imaginario social cuya función es la de promover la cohesión de la colectividad en torno de y contra si mismo (un chivo expiatorio). Se busca desplazar la investigación en dirección a los mecanismos y necesidades psíquicas y 
sociales que fomentan la psicodinámica de la expiación, o el engendramiento de chivos expiatorios.

Palabras claves: Psicoanálisis, perversión, Medicina Legal, chivos expiatorios

(De la perversion à l'expiation: un changement de perspective)

Cet article a comme but d'analyser l'influence de la Médecine Légale sur la délimitation de l'idée de la perversion, ainsi que d'élaborer une nouvelle approche qui identifie le pervers comme une entité de l'imaginaire social dont la fonction est de renforcer la cohésion de la collectivité à travers et contre elle-même - le bouc émissaire. Cette recherche porte sur les mécanismes et les besoins psychiques et sociaux qui fomentent la psychodynamique de l'expiation, soit la genèse des boucs émissaires.

Mots clés: Psychanalyse, perversion, Médecine Légale, boucs émissaires

(From perversion to expiation: a change in perspective)

The influence of legal medicine on the delimitation of the concept of perversion is analyzed here. In the process, a different approach is described, one that identifies the pervert as a figure of social imagery whose function is to bring about social cohesion around and against itself - the scapegoat. The focus of research moves toward mental and social mechanisms, as well as needs that stimulate the psychodynamics of expiation, in other words, in the engendering of scapegoats.

Key words: Psychoanalysis, perversion, legal medicine, scapegoat

Citação/Citation: Frota Neto, E. H.; Rudge, A. M. Da perversão à expiação: uma mudança de perspectiva. Revista Latinoamericana de Psicopatologia Fundamental, São Paulo, v. 12, n. 1, p. 31-44, mar. 2009.

Editor do artigo/Editor: Prof. Dr. Manoel Tosta Berlinck.

Recebido/Received: 20.1.2008 / 1.20.2008 Aceito/Accepted: 25.2.2008 / 2.25.2008

Copyright: (C) 2009 Associação Universitária de Pesquisa em Psicopatologia Fundamental/ University Association for Research in Fundamental Psychopathology. Este é um artigo de livre acesso, que permite uso irrestrito, distribuição e reprodução em qualquer meio, desde que o autor e a fonte sejam citados/This is an open-access article, which permits unrestricted use, distribution, and reproduction in any medium, provided the original author and source are credited. 
Financiamento/Funding: Os autores declararam não ter sido financiados ou apoiados/The authors have no support or funding to report.

Conflito de interesses: Os autores declararam que não há conflito de interesses/The authors declare that they have no conflict of interest.

\section{Eduardo Hugo Frota Neto}

Doutorando em Psicologia Clínica, com a pesquisa Psicanálise: clínica e cultura, pela Pontifícia Universidade Católica do Rio de Janeiro - PUC/RJ (Rio de Janeiro, RJ, Brasil).

R. Fernando Osório, 9/602 - Flamengo.

22230-040 Rio de Janeiro, RJ - Brasil

Fone: (21) 3042-1291

e-mail: edufrotaneto@gmail.com

\section{Ana Maria Rudge}

Membro Psicanalista da Sociedade de Psicanálise Iracy Doyle (Rio de Janeiro, RJ, Brasil); professora do Departamento de Psicologia da Pontifícia Universidade Católica do Rio de Janeiro - PUC/RJ (Rio de Janeiro, RJ, Brasil); Pesquisadora do CNPq; Pesquisadora da Associação Universitária de Psicopatologia Fundamental (São Paulo, SP, Brasil).

R. Marquês de São Vicente, 225 - Edifício Cardeal Leme, sala 201 - Gávea 22453-900. Rio de Janeiro, RJ - Brasil

Fone: (21) 3527-1185

e-mail: arudge@puc-rio.br; ana.rudge@uol.com.br 